\title{
Body Scars and Dorsal Fin Disfigurements as Indicators of Interaction Between Small Cetaceans and Fisheries Around the Mozambique Channel Island of Mayotte
}

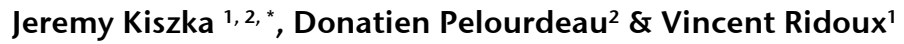 \\ ${ }^{1}$ LIENSS (LIttoral, ENvironnement et Sociétés), UMR 6250, CNRS-Université de La Rochelle, 2, rue Olympe \\ de Gouges, F-17000, La Rochelle, France; 'Direction de l'Environnement et du Développement Durable, \\ Collectivité Départementale de Mayotte. BP 101 F-97600 Mamoudzou, Mayotte
}

\begin{abstract}
Keywords: Dorsal fin, scars, longline fishery, handline, short-finned pilot whale, Globicephala macrorhynchus, Indo-Pacific bottlenose dolphin, Tursiops aduncus, melon-headed whale, Peponocephala electra, Mayotte, Mozambique Channel
\end{abstract}

\begin{abstract}
Cetacean bycatch in fisheries occur in all oceans of the world and may have both lethal and non-lethal consequences (body injuries). In the lagoon of Mayotte (12 $2^{\circ} 50^{\prime} \mathrm{S}, 45^{\circ} 10^{\prime} \mathrm{E}$ ), in the northern Mozambique Channel, two main types of fisheries occur: handlining (inside the lagoon) and longlining (outside the barrier reef, over the 'continental' slope). The level of interactions between small cetaceans and fisheries in this area were characterised using identification photographs taken from July 2004 to April 2008 during dedicated cetacean surveys. Photographs were taken of Indo-Pacific bottlenose dolphins (Tursiops aduncus), melon-headed whales (Peponocephala electra) and short-finned pilot whales (Globicephala macrorhynchus). Injuries on the dorsal region (especially the dorsal fin) were characterised and related to fisheries or intra-/ inter-specific interactions (with sharks and other cetacean species). The results suggest interactions with fisheries involving the three species around Mayotte. The occurrence of interactions was the highest in the most coastal species, i.e. T. aduncus. This study shows that interactions between fisheries and small cetaceans occur at varying levels around Mayotte. It also confirms the utility of scars as indicators of fishery exposure to cetaceans.
\end{abstract}

\section{INTRODUCTION}

Interactions between marine mammals (cetaceans, pinnipeds and sirenians) and fisheries occur worldwide and affect many species in most fisheries. Marine mammals are known to interact with fisheries at different levels. When fisheries and these predators exploit the same targeted species, they interact ecologically through trophic pathways. In other cases, interactions are operational, marine mammals being incidentally captured in fishing gear when both fisheries and marine mammals occur in the same area (Beverton, 1985). Such interactions have occurred for centuries and have increased in frequency and intensity during the last decades (DeMaster et al., 2001). Between 1990 and 1994, it is estimated that globally, 653365 marine mammals were taken accidentally in fishing gears (Read $e t$ al., 2006). This estimate, while extrapolated, shows the huge potential impact on species' demographic parameters and survival. In addition, major adverse ecological impacts of fisheries are closely related to the bycatch issue (Lewison et al., 2004). The incidental mortality of marine mammals in fishing gear, as well as other large marine megafauna such as seabirds, sea turtles and sharks, is probably the most direct threat to these species on a worldwide 
scale. Thus, it is critical that this threat is clearly identified as part of the management process, especially if it directly threatens the survival of a species in a given area.

In inshore waters, gillnetting is unselective and is known to threaten regional stocks of marine mammals, such as the vaquita, Phocoena sinus, in the Gulf of Mexico (D'Agrosa et al., 2000), and species in the coastal waters of developing countries are especially threatened (Read et al., 2006). In offshore areas, bycatch in the eastern tropical Pacific purse-seine fishery has been extensively described, and populations of north-eastern offshore spotted dolphins (Stenella attenuata attenuata) and eastern spinner dolphins (Stenella longirostris orientalis) have been reduced and are not recovering (Gerrodette \& Forcada, 2005). Identifying fishery interactions can be done in a variety of ways, including using observers on fishing vessels, the examination of wounds, scars or entangled gear on beach-cast animals, observation of animals in the wild with entangled fishing gear, questionnaire surveys of fishermen, and the examination of the rates and patterns of entanglement-related scarring visible in photographs of animals in the wild (see for example Romanov, 2001; Friedlaender et al., 2001; Robbins \& Mattila, 2001; Baird et al., 2002; Baird \& Gorgone, 2005). This latter technique, for at least some species, may result in more accurate estimates of fisheries interactions than those available from examination of beach-cast animals or opportunistic observations of animals carrying fishing gear (Baird \& Gorgone, 2005).

Mayotte, in the north-eastern Mozambique Channel (Comoros archipelago) is a fast developing island under French administration. The fisheries around Mayotte are artisanal. However, due to the increasing human population, fishing pressure is on the increase (Direction des Affaires Maritimes, unpublished data). The most important fishery uses hand lines, targeting reef fishes, especially predatory demersal species such as groupers and snappers. In 2006, 1,092 small boats (including outrigger canoes or 'pirogues' and simple open boats 'barks' less than $7 \mathrm{~m}$ length) have been censused by the local fishing service (Kiszka et al., this volume). Other fishing techniques include small seines deployed on barrier and fringing reefs (less than 20 'barks'). Three long-liners are based in Mayotte and fish in the territorial waters, targeting swordfish (Xiphias gladius) and tunas, and deploying between 400 and 700 hooks each.

From July 2004 to April 2008, regular boatbased surveys allowed us to describe diversity, distribution and abundance of cetaceans around Mayotte. During these surveys, the collection of photographs of the dorsal fin region allowed individual identification of several delphinid species as well as documenting the presence of traumatic lesions related to interactions with fisheries. This paper presents the characteristics of these lesions and their occurrence in three species occurring around the island: the Indo-Pacific bottlenose dolphin (Tursiops aduncus), living in inshore and lagoon waters around the island, and two oceanic species living offshore, the melon-headed whale (Peponocephala electra) and the short-finned pilot whale (Globicephala macrorhynchus).

\section{MATERIALS AND METHODS}

\section{Study area}

Mayotte $\left(45^{\circ} 10^{\prime} \mathrm{E}, 12^{\circ} 50^{\prime} \mathrm{S}\right)$ is almost entirely surrounded by a $197 \mathrm{~km}$ long barrier reef, with a second double-barrier in the southwest and the immerged reef complex of Iris, in the northwest (Figure 1). There are a series of deep passes through the reefs, some of which are the sites of old rivers (Quod et al., 2000). The inner lagoon has an area of 1,200 $\mathrm{km}^{2}$ with an average depth of $20 \mathrm{~m}$, but reaches a maximum depth of $80 \mathrm{~m}$ in the west. The main island is surrounded by a fringing reef $(195 \mathrm{~km})$, which is interrupted by river mouths. The diversity of marine mammals is very high (20 species), in a very restricted area (around 2,500 $\mathrm{km}^{2}$ ) around the island (Kiszka et al., 2007). The 'continental' slope is very steep around the barrier reef and contains many submarine canyons.

\section{Data collection and analysis}

From July 2004 to April 2008, dedicated cetacean surveys, varying in length and objectives, were conducted around Mayotte, both inside and outside the lagoon. Surveys were conducted throughout the study period during daylight hours, i.e. between 


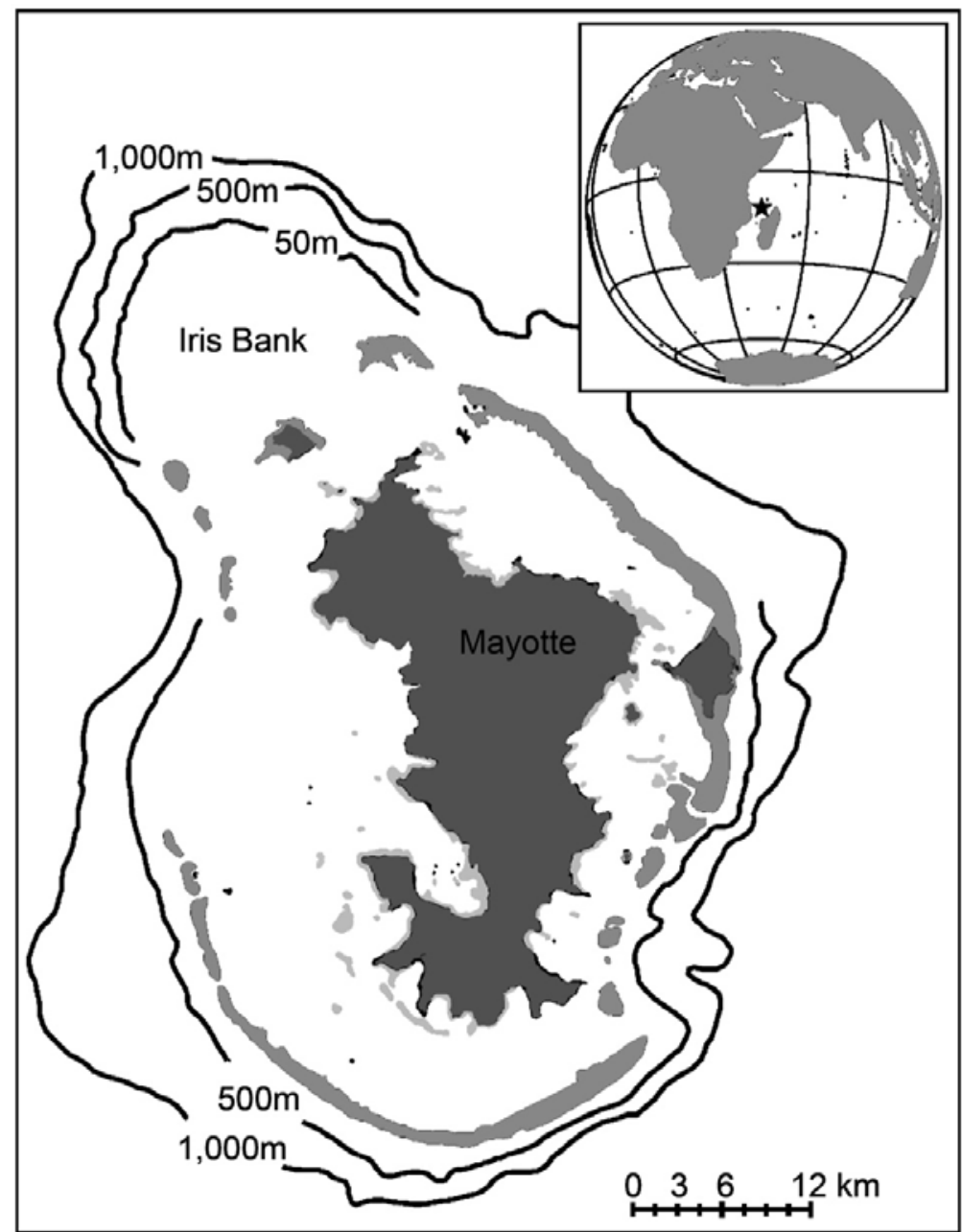

Fig. 1. The lagoon of Mayotte, in the Mozambique Channel (southwest Indian Ocean)

$0700 \mathrm{~h}$ and $1800 \mathrm{~h}$, in sea conditions with winds not exceeding Beaufort 3. Several types of boats were used: a 7 meter catamaran equipped with two, four-stroke, 60-hp outboard engines; a 7 meter boat equipped with two, two-stroke, 40-hp outboard engines, a 6.40 meter cabin boat equipped with one, four-stroke 150-hp outboard engine and a 10.80 meter cabin boat equipped with two, four stroke, 115-hp outboard engines. Survey vessels did not follow pre-defined transects but every attempt was made to sample each habitat type within the surrounding waters of Mayotte. Observation efforts concentrated mostly in the lagoon, and over the 'continental' slope. From July 2004 to April 2008, a total amount of 908.6 hours was spent actively searching for marine mammals around Mayotte (equivalent to 172 days).
For each sighting, the species, group size (maximum, minimum, best estimate), geographic position and primary behaviour activity (travelling, resting, foraging/feeding, socialising, milling, play), group classification on the basis of relative size of individuals (adults, sub-adults, calves), research boat disturbance (bowride, approach, avoidance, no response) as well as group formation (tight, loose, dispersed, variable, convergent) were recorded (see Shane, 1990; Würsig et al., 1998). During encounters, photographs of the dorsal fin region were taken. An attempt was made to photograph all individuals present in the group. Colour photographs were taken with a digital $35 \mathrm{~mm}$ camera equipped with a $100-300 \mathrm{~mm}$ lens. Individual photo-identification using physical 
characteristics of the dorsal fin was undertaken, following the method of Würsig \& Jefferson (1990) and Bearzi et al. (1997) for bottlenose dolphins. It has also been applied to short-finned pilot whales and melon-headed whales (Miyashita et al., 1992; Kiszka \& Pelourdeau, unpublished data). Only good quality pictures were used to identify individuals (perpendicular angle of the picture to the dorsal fin, good clarity and close proximity). Two types of individuals were defined, based on the presence of distinctive features on their dorsal fin: 1) individuals without any nicks and any other distinctive feature on their dorsal fin (including shape of the dorsal fin), and 2) individuals with nicks and distinctive features, even very small notches. Injuries on the dorsal fin and occasionally other parts of the body were examined from available photographs.

Two types of scars were defined:

- Marks and injuries unequivocally due to fishing gears (lines and/or nets). These individuals have major linear dorsal fin mutilations, nicks and body scars, such as linear marks that have been previously described and attributed to fishing lines (Baird \& Gorgone, 2005). They can also have remains of fishing gears on their body.

- Marks and injuries due to intra-specific social interactions or with other species (cetaceans, sharks). These individuals have non-linear dorsal fin mutilations, nicks and body scars.

In order to compare exposure to fishing gears among species, we calculated a simple specific "fishing gear exposure risk ratio" $\left(\mathrm{R}_{\mathrm{i}}\right)$ :

$$
\mathrm{R}_{\mathrm{i}}=\left(\mathrm{N}^{\text {dis. }} / \sum^{\text {id. }}\right) \% \text { id. }
$$

Where $\mathrm{N}$ dis. is the number of individuals having clear evidence of fishery interaction, $\Sigma$ id. is the total number of identified individuals, and $\%$ id. is the proportion of identifiable individuals.

\section{RESULTS}

\section{Cetacean encounters}

From July 2004 to April 2008, 445 marine mammal sightings were documented.

Indo-Pacific bottlenose dolphins were encountered on 85 occasions. Group size was relatively small $($ mean $=6.1 ; \mathrm{SD}=3.5 ; \mathrm{min} .=1$; max.=15). Groups included all age classes, including calves. Bottlenose dolphins were observed inside the lagoon or over reef banks (less than $100 \mathrm{~m}$ deep). Melon-headed whales were encountered on nine occasions. Groups were very large $($ mean $=288$; $\mathrm{SD}=84 ; \min .=140 ; \max .=450$ ), and included all age classes. Sightings occurred along the barrier reef, outside the lagoon over the 'continental' slope (21 to $1,100 \mathrm{~m})$. There were five encounters of shortfinned pilot whales. Group size ranged from 30 to 80 individuals (mean=58; $\mathrm{SD}=19$ ). All age classes were observed on each encounter (adult males and females, sub-adults and calves). Sightings occurred outside the lagoon, east and south-east of the island in waters of varying depths (60 to $1,800 \mathrm{~m}$ ).

\section{Photo-identification effort}

Photo-identification sessions were conducted for Indo-Pacific bottlenose dolphins ( $\mathrm{n}=35$ sessions), melon-headed whales $(n=9)$, and short-finned pilot whales $(n=5)$. For bottlenose dolphins, 42 individuals were identified (all adults), while 255 melon-headed whales and 45 short-finned pilot whales were also identified. Overall proportions of identifiable individuals varied among species: $79 \%$ for T. aduncus, $81 \%$ for melon-headed whales and $60 \%$ for short-finned pilot whales.

\section{Dorsal scars in Indo-Pacific bottlenose dolphins}

Among the 42 identifiable Indo-Pacific bottlenose dolphins, eight (19\%) showed significant marks and injuries that could be related to interactions with fisheries or attributable to intra- or inter-specific interactions (with conspecifics, other cetacean species or predators, such as sharks). Among them, two showed signs of probable shark attack (individual TA_MAY032 while TA_MAY012 also shows evidences of interaction possibly a Risso's dolphin, Grampus griseus, Figure 2). Four individuals showed evidence of interaction with fishing gear. Three individuals showed significant dorsal fin mutilation that could be related to fishing gear interactions (Figure 3). Other individuals have linear marks and mutilations of lesser importance that were observed on the dorsal fin or at its base (individuals TA_MAY004 and TA_MAY005, Figure 4). Individual TA_MAY021 (Figure 4) is 


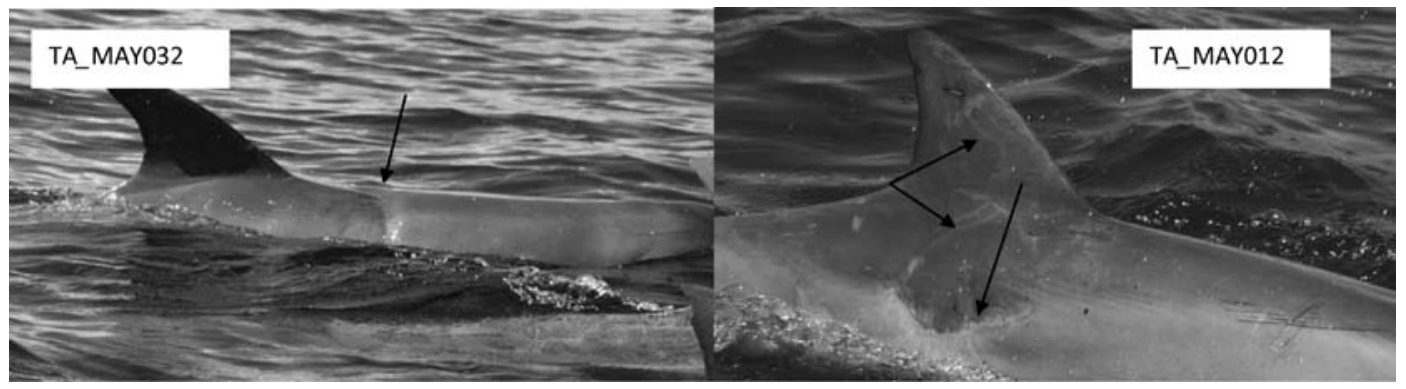

Fig. 2. Indo-Pacific bottlenose dolphins: individuals TA_MAY032 and TA_MAY0012, showing injuries probably related to a shark interaction. Individual TA_MAY012 also show signs of interaction with another delphinid species (probably Grampus griseus)

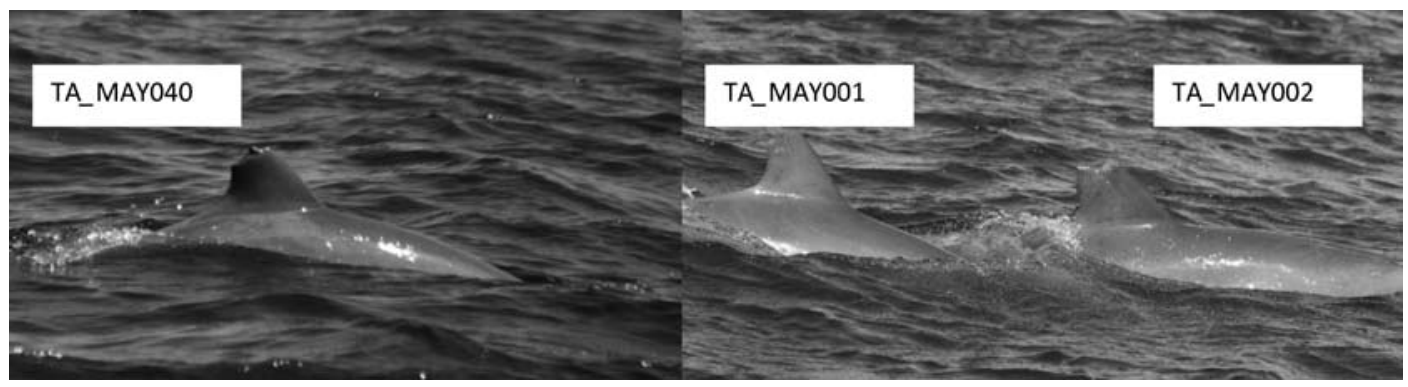

Fig. 3. Indo-Pacific bottlenose dolphins: individuals TA_MAY040, TA_MAY001 and TA_MAY002, show dorsal fin mutilations, probably due to fishing line interaction

characterised by suspicious deep nick on the upper part of the peduncle, that could be due to fishing gear interaction. A fourth individual (not identifiable as it is a calf) has been observed (Figure 4, bottom right) with the remains of a handline around its beak. The exposure risk ratio is 0.15 for bottlenose dolphins (Table 1).

\section{Dorsal scars in melon-headed and short- finned pilot whales}

Dorsal fin abrasion was very frequently observed in melon-headed whales (56.3\% of identified whales). Most of these dorsal fin abrasions seem linked to inter-individual interactions (see individuals PE_MAY049 and PE_MAY124, Figure 5). Four cases of dorsal fins cut at the leading edge have been observed, likely due to fishing gear interaction (individuals PE_MAY091 and PE_MAY019, Figure 5). The exposure risk ratio is 0.01 (Table 1).

Of the 45 pilot whales identified, six showed important dorsal fin scars. Two were probably attributable to a fishing line, and the others were related to intra-specific interactions (individuals
GM_MAY020 and GM_MAY025, Figure 6). The exposure risk ratio is 0.02 (Table 1).

\section{DISCUSSION}

Body scars, dorsal fin disfigurements and mutilation have been previously described for a number of odontocetes, including killer whales (Orcinus orca) in British Columbia (Bigg et al., 1987), false killer whales (Pseudorca crassidens) in Hawaii (Baird \& Gorgone, 2005) and common bottlenose dolphins (T.truncatus) in Queensland, Australia (Corkeron et al., 1987). Both natural and anthropogenic sources have been identified, including interactions with predatory sharks (Corkeron et al., 1987), intraspecific interactions (Chu \& Nieukirk, 1988) and interactions with fishing gears such as longlines and gillnets (Baird \& Gorgone, 2005; Razafindrakoto et al., 2007).

In small cetaceans around Mayotte, we suggest that dorsal fin disfigurement and other body scars are due to both predatory interactions and, more importantly, to fishing gear interactions. Dorsal fin mutilations, and other scars on the dorsal fin region, 


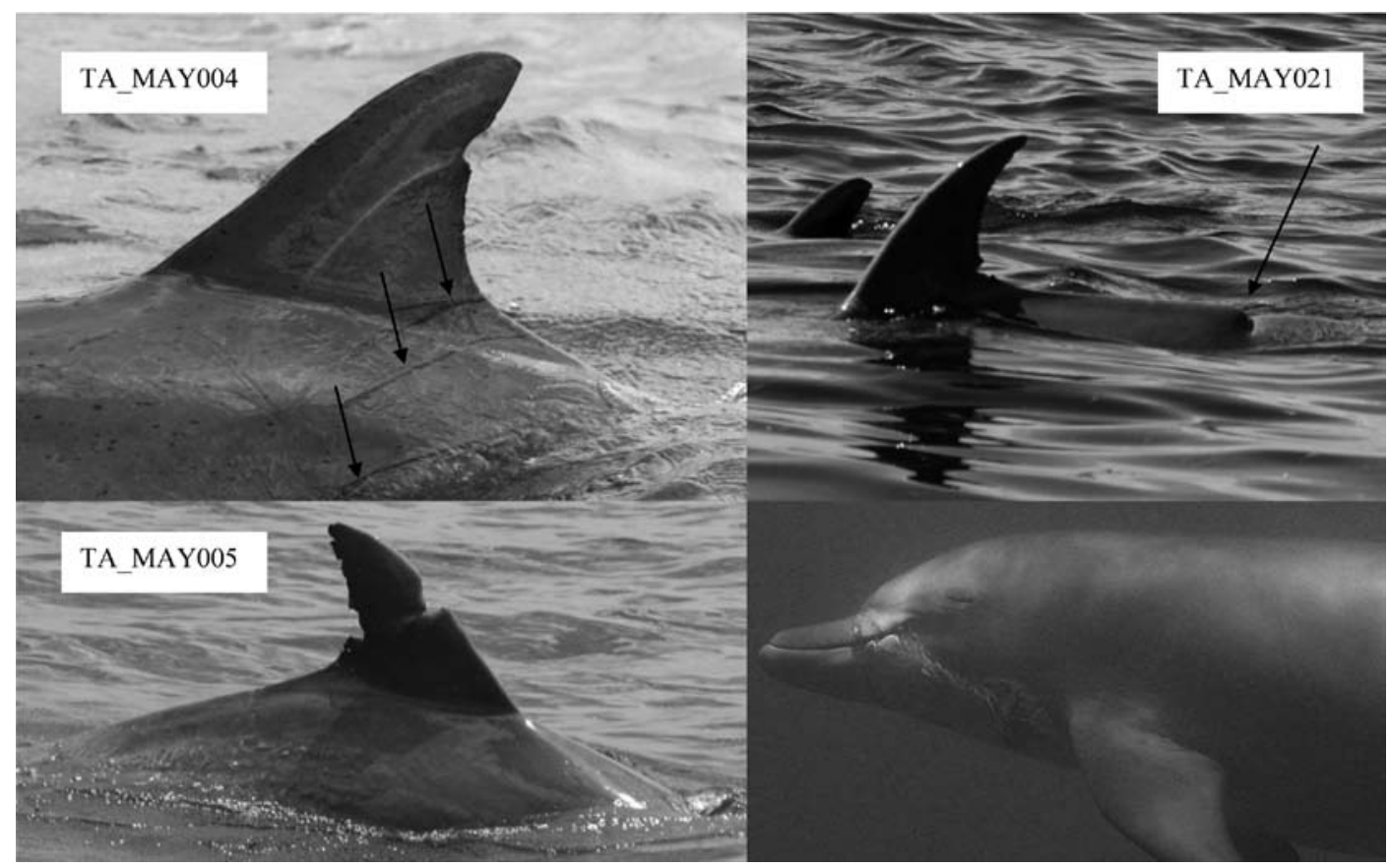

Fig. 4. Indo-Pacific bottlenose dolphins: individuals TA_MAY004, TA_MAY021 and TA_MAY005 showing dorsal fin and body scars certainly due to fishing gears (probably handline). The underwater picture (bottom right) shows an unidentified calf having remains of handline around the beak

Table 1. Species distribution and exposure risk ratios $\left(\mathbf{R}_{\mathrm{i}}\right)$, where $\mathbf{N}^{\text {dis }}$ is the number of individuals having clear evidence of fishery interaction, $\Sigma^{\text {id }}$ the total number of identified individuals and $\%$ id. the mean proportion of identifiable individuals

\begin{tabular}{lccc}
\hline & Coastal/lagonal species & \multicolumn{2}{c}{ Oceanic species } \\
\cline { 2 - 4 } Parameter & Tursiops aduncus & Peponocephala electra & Globicephala macrorhynchus \\
\hline $\mathrm{N}$ dis. & 8 & 4 & 2 \\
$\Sigma^{\text {id. }}$ & 42 & 255 & 45 \\
$\%^{\text {id. }}$ & 0.79 & 0.81 & 0.6 \\
$\mathbf{R}_{\mathbf{i}}$ & $\mathbf{0 . 1 5}$ & $\mathbf{0 . 0 1}$ & $\mathbf{0 . 0 2}$ \\
\hline
\end{tabular}

are certainly due to fishing lines. Other gears such as gillnets have never been used in the lagoon of Mayotte. Shark bite wounds (two cases recorded) are typically jagged, and dorsal fin injuries from sharks appear rare compared with injuries on other parts of the body (Heithaus, 2001).

Body scars and dorsal fin disfigurement have been observed on the three species investigated. While several individuals were characterized by ambiguous injuries (either due to anthropogenic or natural sources), several cases show clear signs of interactions with fishing gears. Through the calculation of exposure risk ratios, we showed that coastal species (especially the Indo-Pacific bottlenose dolphin) were more affected by fisheries that oceanic species (melon-headed and pilot whales). Inside the lagoon of Mayotte and on adjacent reef banks, hand lining is the commonest fishing technique (Direction des Affaires Maritimes, unpublished data). In 2007, an interview survey conducted with 406 fishermen documented three dolphins bycaught with handlines (Pusineri \& Quillard, this volume). It confirms that there is a possible link between dorsal fin disfigurement (and other body scars) and mortality, at least for Indo-Pacific bottlenose dolphins. Another instance 


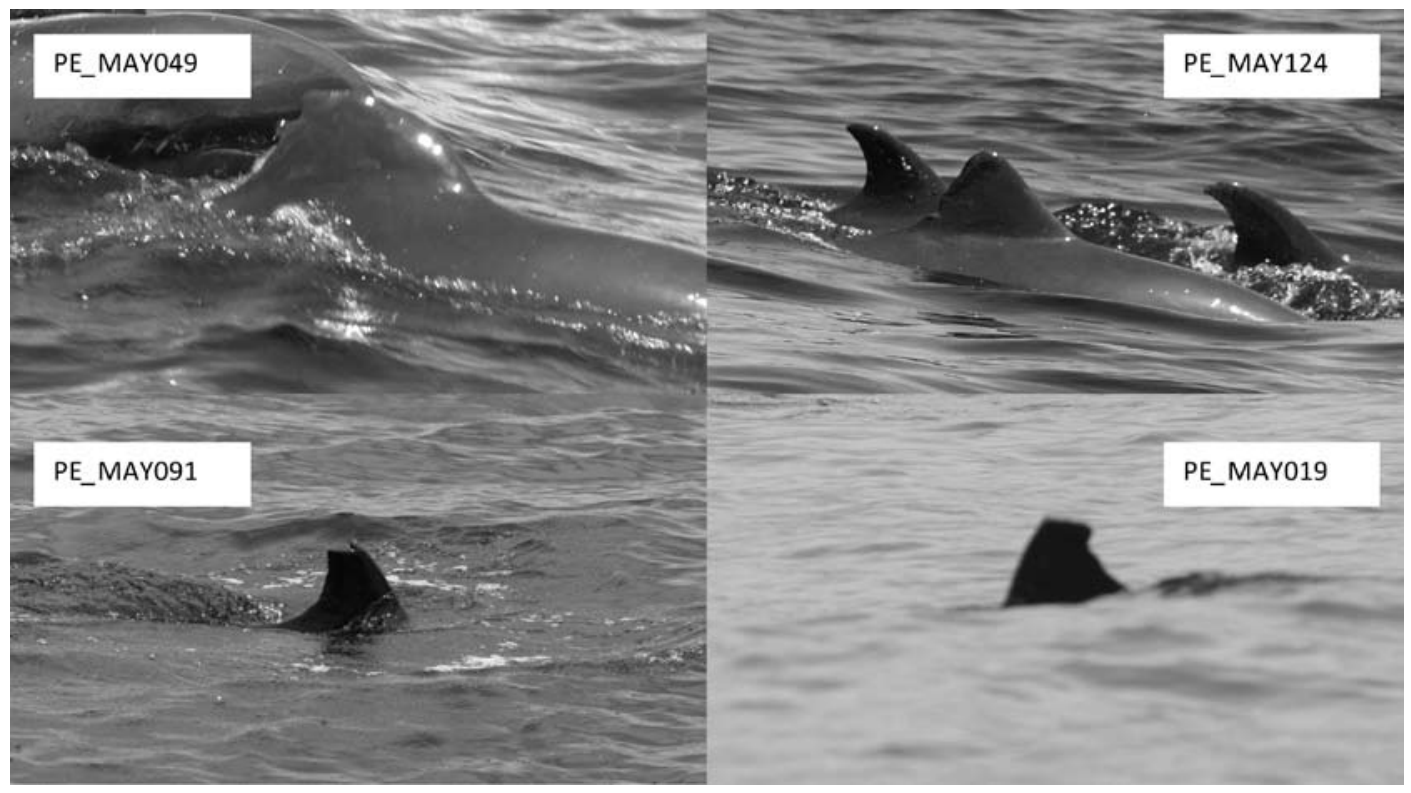

Fig. 5. Melon-headed whales: individuals PE_MAY049 and PE_MAY124 showing non linear dorsal fin abrasion, certainly due to intra-specific interactions. Individuals PE_MAY091 and PE_MAY019 have linear section of the leading edge of the dorsal fin, probably due to interaction with fishing line

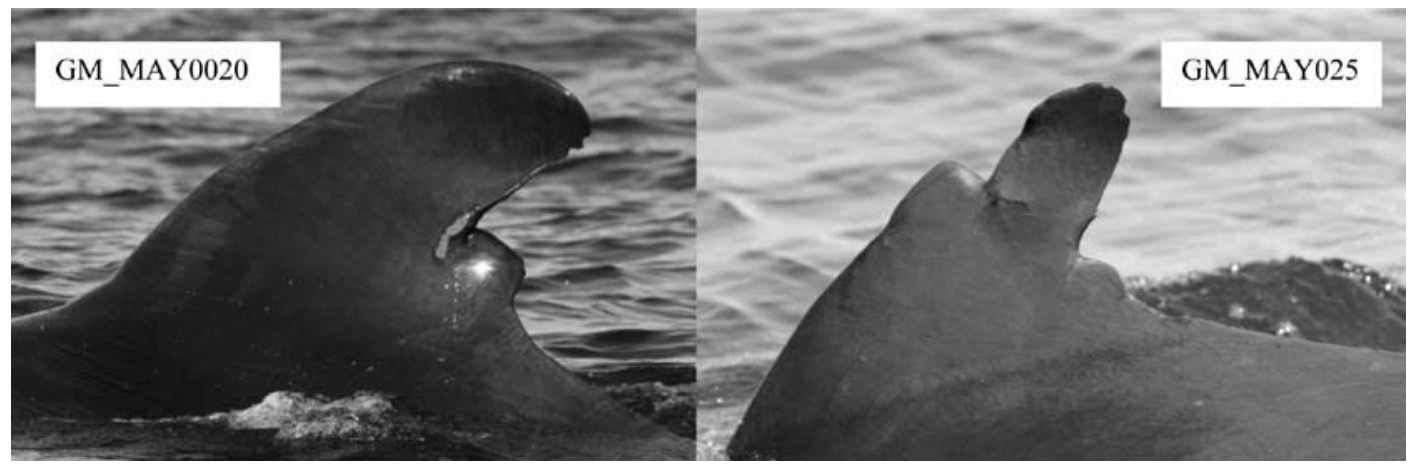

Fig. 6. Short-finned pilot whales: individuals GM_MAY020 and GM_MAY025 having dorsal fin injuries probably due to fishing line interactions

of this phenomenon is documented in this paper, as a bottlenose dolphin calf has been observed for several months with remains of a handline around its beak. Taking into consideration existing mortalities, the existence of non-lethal injuries in some identified individuals, the low abundance and high degree of site fidelity of inshore bottlenose dolphins (Kiszka \& Pusineri, 2006), as well as the increasing fishing effort in the lagoon of Mayotte, handlining could negatively impact Indo-Pacific bottlenose dolphins in this area. This has to be taken into account for future research on this species around Mayotte.
For oceanic species, such as melon-headed and short-finned pilot whales, a few cases of fisheries interactions were reported in the present study. The high rate of injuries observed on pilot whales suggests regular interactions between this species and the commonest fishery in the area, i.e. longlining. This species is known to interact with longline fishery elsewhere in the world and in the Indian Ocean, in places such as around Reunion Island (Poisson et al., 2001; Garrison, 2007). The low occurrence of dorsal fin disfigurement in melon-headed whales suggests that interactions rarely occur between this species and the longline 
fishery, or that individuals are killed in such interactions. Longlining in Mayotte is artisanal and only three boats operate in territorial waters. Cases of cetacean-longline fishery interactions have been observed during the last five years, involving short-finned pilot whales (bulk of observations), false killer whales, spinner dolphins (for baits) and melon-headed whales (one observation; F. Fredericci \& G. Wunderlee, pers. comm.). The occurrence of injuries in both species around Mayotte confirms this trend. Mortalities have only been observed for a spinner dolphin, but depredation due to pilot whales regularly occurs (G. Wunderlee, pers. comm.).

The rates of scarring and disfigurement due to fishing gears are significant around Mayotte. Baird and Gorgone (2005) documented rates of major dorsal fin disfigurement (completely missing or bent over at base) for odontocete populations. Major rates were observed on false killer whales and bottlenose dolphins around Hawaii and on bottlenose dolphins in North Carolina (Baird \& Gorgone, 2005). Around Mayotte, dorsal fins are not completely missing, but can be partially missing or are characterized by relatively clear signs of interaction with fishing gear.

As observer programs are difficult to establish for artisanal fisheries, and strandings are very rare around Mayotte, which may be due to the high presence of scavengers such as sharks, the combined use of interview surveys (Pusineri \& Quillard, this volume) and the study of occurrence of dorsal fin/body scars from photo-identification is highly valuable in evaluating cetacean-fishery interactions, and could be used as an indicator of mortality due to fishing gear. The use of these methods would be recommended for similar developing countries where fishing pressure is high.

Acknowledgements: We thank Nils Bertrand (Sea Blue Safari, whale-watching tour guide) for providing opportunistic information on short-finned pilot whales and Indo-Pacific bottlenose dolphins around Mayotte. Claire Pusineri (Office National de la Chasse et de la Faune Sauvage) contributed to the analysis of photo-identification data of IndoPacific bottlenose dolphins. This work has been possible with the financial support of the French Ministry of Environment (MEDD), the Collectivité
Départementale de Mayotte and the participation of the Direction de l'Agriculture et de la Forêt as well as the Office National de la Chasse et de la Faune Sauvage. Special thanks are addressed to fishermen of the longline fishery in Mayotte (Fabien Fredericci, Sébastien Labarte and Gérard Wounderlee) for the information they provided. A special thank is addressed to Robin W. Baird (Cascadia Research Collective, Canada) for helpful comments on the early version of the manuscript.

\section{REFERENCES CITED}

Baird, R.W. \& Gorgone, A.M. (2005). False killer whale dorsal fin disfigurements as a possible indicator of long-line fishery interactions in Hawaiian waters. Paci. Sci., 59: 593-601.

Baird, R.W., Stacey, P.J., Duffus, D.A. \& Langelier, K.M. (2002). An evaluation of gray whale (Eschrichtius robustus) mortality incidental to fishing operations in British Columbia, Canada. J. Cet. Res. Manage., 4: 289-296.

Bearzi, G., Notarbartolo-di-Sciara, G. \& Politi, E. (1997). Social ecology of bottlenose dolphins in the Kvarneric (northern Adriatic Sea). Mar. Mammal Sci., 15: 1065-1097.

Beverton, R.J.H. (1985). Analysis of marine mammalfisheries interactions. In J.R. Beddington, R.J.H. Beverton \& D.M. Lavigne (Eds.). Marine Mammals and fisheries. George Allen \& Unwin, London. Pp. 3-33.

Bigg, M.A., Ellis, G.M., Ford, J.K.B. \& Balcomb, K.C. (1987). Killer whales: a study of their identification, genealogy, and natural history in British Columbia and Washington State. Phantom Press, Nanaimo, British Columbia, Canada.

Chu, K. \& Nieukirk, S. (1988). Dorsal fin scars as indicators of age, sex, and social status in humpback whales (Megaptera novaeangliae). Can.J. Zool., 66: 416-420.

Corkeron, P.J., Morris, R.J. \& Bryden, M.M. (1987). Interactions between bottlenose dolphins and sharks in Moreton Bay, Queensland. Aquat. Mamm., 13: 109-113.

D’Agrosa, C., Lennert-Cody, C.E. \& Vidal, O. (2000). Vaquita bycatch in Mexico's artisanal gillnet fisheries: driving a small population to extinction. Cons. Bio., 14: 1110-1119.

DeMaster, D.J., Fowler, C.W., Perry, S.L. \& Richlen, M.E. (2001). Predation and competition: the impact of fisheries on marine mammal populations over the next one hundred years. J. Mammal., 82: 641-651. 
Friedlaender, A.S., McLellan, W.A. \& Pabst, D.A. (2001). Characterising an interaction between coastal bottlenose dolphins (Tursiops truncatus) and the spot gillnet fishery in south-eastern North Carolina, USA. J. Cet. Res. Manage., 3: 293-303.

Garrison, L.P. (2007). Interactions between marine mammals and pelagic longline fishing gear in the U.S.Atlantic Ocean between 1994 and 2004. Fish. Bull., 105: 408-417.

Gerrodette, T. \& Forcada, J. (2005). Non-recovery of two spotted and spinner dolphin populations in the eastern tropical Pacific Ocean. Mar. Ecol. Prog. Ser., 291: 1-21.

Heithaus, M. (2001). Shark attacks on bottlenose dolphins (Tursiops aduncus) in Shark Bay, Western Australia: attack rate, bite scar frequencies and attack seasonality. Mar. Mamm. Sci., 17: 526-539.

Kiszka J, Pusineri C (2006) Les delphinidés autour de Mayotte : structure des groupes, distribution, abondance et budgets d'activité. Rapport d'étude 2005-2006. Observatoire des Mammifères Marins de Mayotte (Direction de l'Agriculture et de la Forêt). $37 \mathrm{pp}$.

Kiszka, J., Ersts, P.J. \& Ridoux, V. (2007). Cetacean diversity around the Mozambique Channel island of Mayotte (Comoros archipelago). J. Cet. Res. Manage., 9: 105-109.

Kiszka, J., Muir, C.E., Amir, O.A., Cox, T.M., Drouot-Dulau, V., Poonian, C., Razafindrakoto, Y. \& Wambiji, N. (this volume). Marine mammal bycatch in the southwest Indian Ocean: review and need for a comprehensive status assessment. West. Ind. Ocean J. Mar. Sci.

Lewison, R.L., Crowder, L.B., Read, A.J. \& Freeman, S.A. (2004). Understanding impacts of fisheries bycatch on marine megafauna. Trends in Ecology and Evolution, 11: 598-604.

Miyashita, T., Kasuya, T. \& Mori, K. (1990). An examination of the feasibility of using photoidentification techniques for a short-finned pilot whale stock off Japan. Rep. int. Whal. Comm. (special issue) 12: 425-428.

Poisson, F., Marjolet, C., Mété, K. \& Vanpouille, M. (2001). Evaluation du phénomène de déprédation dû aux mammifères marins. In F. Poisson \& M. Taquet (Eds.). L'espadon: de la recherche à l'exploitation durable. Programme Palangre Réunionnais. IFREMER. Pp. 231-247.

Pusineri, C. \& Quillard, M., this volume. Bycatch and direct captures of protected megafauna by the artisanal coastal fishery of Mayotte. West. Ind. Ocean J. Mar. Sci.

Quod, J.P., Naim, O. \& Abdourazi, F. (2000). The Comoros archipelago. In: C. Sheppard (Ed.). Seas at the Millennium: an environmental evaluation. Pergamon Press, Oxford. Pp. 243-252.

Razafindrakoto, Y., Andrianarivelo, N., Cerchio, S., Rosenbaum, H.C. \& Rasoamananto, I., 2007. Assessing the extent of cetacean bycatch in the artisanal gillnet fisheries and direct captures in the south-western region of Madagascar. Pp: 45-52. In: J. Kiszka \& C. Muir (Eds.). Incidental catch of non-targeted marine species in the western Indian Ocean : problems and mitigation measures. Workshop proceeding. 13-15th November 2006, Mayotte, France. 111p.

Read, A.J., Drinker, P. \& Northridge, S. (2006). Bycatch of marine mammals in U.S. and global fisheries. Cons. Bio., 20: 163-169.

Robbins, J. \& Mattila, D.K. (2001). Monitoring entanglements of humpback whale (Megaptera novaeangliae) in the Gulf of Maine on the basis of peduncle scarring. Document SC/53/ $\mathrm{NAH} 25$ presented to the International Whaling Commission Scientific Committee.

Romanov, E.V. (2001). Bycatch in the tuna purse-seine fishery in the western Indian Ocean. Fish. Bull., 100: $90-105$.

Shane, S.H. (1990). Behaviour and ecology of the bottlenose dolphin at Sanibel Island, Florida. In S. Leatherwood \& R.R. Reeves (Eds.) The Bottlenose dolphin. Academic Press: San Diego (CA); 245-265.

Würsig, B. \& Jefferson, T.A. (1990). Methods of photo-identification for small cetaceans. Rep.int. Whal. Comm. (special issue) 12: 43-52.

Würsig, B., Lynn, S.K., Jefferson, T.A. \& Mullin, K.D. (1998). Behaviour of cetaceans in the Northern Gulf of Mexico relative to survey ships and aircraft. Aquat. Mamm., 24: 41-50. 
